\title{
Test Analysis and Theoretical Calculation on Braking Distance of Automobile with ABS
}

\author{
Dongsheng Wu, Jun Li, Xiaoping Shu, Xiaojing Zha, and Beili Xu \\ School of Mechanical and Electronic Engineering, East China Jiaotong University, \\ Nanchang 330013, P.R. China
}

\begin{abstract}
Braking performance test methods are compared and analyzed. ABS will not work if the speed is too low when the automobile is tested by tester and load testing. Since the braking performance can not be evaluated accurately in this case, the theoretical calculation of braking distance is given in this paper. The calculation result shown the potential of braking performance is mainly on high speed for the automobile with ABS. High-speed road test is designed, and the test results are close to calculation ones, so calculation model is of accuracy. It is less error and better precision than existing calculation way, this method is effective and accurate.
\end{abstract}

Keywords: Automobile with ABS, Testing, Braking distance, Theoretical calculation.

\section{Introduction}

The ABS automobile is a vehicle with anti-lock braking system. The Braking performance reflects the ability that the vehicle stops in a short time and keeps traveling stability. The braking distance is the distance required for a vehicle moving at a specified velocity to come to a complete stop after its brakes have been activated. It is an important indicator for braking performance evaluation, but the error is big for braking distance test of automobiles with ABS[1]. So its performance can't be accurately shown from test results[2].

Therefore, the ABS braking distance is simulated through this theory method. Simulation results must be compared with the road test to verify the simulation accuracy. For the road test of ABS brake performance, the United States, Japan and the European Economic Community, Economic Commission for Europe have enacted stringent norms and regulations, and also put forward specific requirements from different perspectives. By theoretical calculation, initial speed in these norms and regulations has been discussed whether it can truly reflect potential braking performance in the line brake. It can be more targeted to amend road test so that the braking performance of vehicle with ABS can be comprehensive evaluated[3-4].

\section{Braking Distance Test of Automobile with ABS}

There are two methods for testing braking performance of automobiles with ABS, one is by tester and the other is by road testing. The brake distance can be measured by road 
testing. At present, towing method is mainly used on the road testing, that is to say, the press and drag mark is used to evaluate the braking performance when a vehicle moving at a specified speed brakes. This method is simple and visual, but the disadvantage is also obvious. This method is limited by many factors such as weather, road, driver[5]. Test data is easily impacted on human and test condition. Therefore, the value is different after many tests and evaluation of braking performance is not exact.

\section{Calculation Method of Braking Distance of Automobile with ABS}

In order to get reference for road test results, calculation equation is derived through analysis of braking process.

\subsection{Establishment of Calculation Model}

The reaction time $t_{0}$ mainly depends on the driver, as well as the positions of accelerator pedal and brake pedal. Usually, it only takes $0.3 \sim 1.0$ seconds so the distance that the vehicle moves during $t_{0}$ at the speed of $v_{0}$ can be ignored according to equation $s_{1}=v_{0} \cdot t_{0}$.

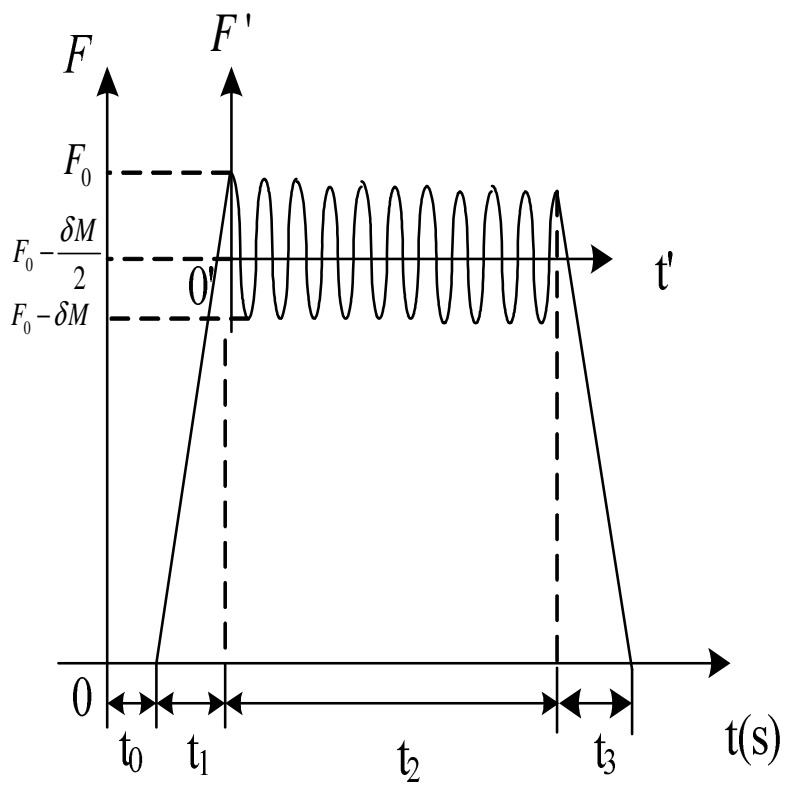

Fig. 1. Braking process of automobile with ABS

The second step is the growth of braking force $t_{1}$. The braking force keeps increasing with the driver moving the brake pedal until it is up to the maximum. Due to the gap between brake shoe and brake drum, braking force will work after a short period of 
time. To compare the results with the one in Reference 6, this period can also be ignored. So the brake reaction time can be regarded as $t_{1}$. At this period, the automobile's braking performance is the best because of ABS working.

Supposed the maximum braking force just reaches the maximum ground braking force, according to the force analysis of wheels during braking, the maximum deceleration $\mathrm{F}_{0}$ is as followed:

$$
F_{0}=\varphi_{p} \cdot g \cdot M
$$

Where, $\varphi_{\mathrm{p}}$ is peak adhesion coefficient, $\mathrm{g}$ is acceleration of gravity, which is $9.8 \mathrm{~m} / \mathrm{s} 2$.

During the growing step of braking force, the growth is a linear function of time, whose average braking force $\overline{F_{1}}$ is:

$$
\bar{F}_{1}=\frac{\int_{0}^{T_{1}} \frac{m g \varphi_{p}}{T_{1}} d T}{T_{1}}=\frac{1}{2} m g \varphi_{p}
$$

In this step, according to Newton's second law, the average deceleration $\mathrm{a}_{1}$ and terminal velocity $\mathrm{v}_{1}$ can be expressed as followed:

$$
\begin{gathered}
a_{1}=\frac{\bar{F}_{1}}{m}=\frac{1}{2} g \varphi_{p} \\
v_{1}=v_{0}-\int_{0}^{t_{1}} \frac{g \varphi_{p}}{t_{1}} t d t=v_{0}-\frac{1}{2} g \varphi_{p} t_{1}
\end{gathered}
$$

According to the functional relationship, the work of braking force on the car is equal to kinetic energy increase before and after braking, so $\overline{F_{1}}$ is:

$$
\bar{F}_{1} \cdot S_{1}=\frac{1}{2} m g \varphi_{p} S_{1}=\frac{1}{2} m v_{0}^{2}-\frac{1}{2} m v_{1}^{2}
$$

Then braking distance of second step s1 is:

$$
S_{1}=\frac{v_{0}^{2}-v_{1}^{2}}{g \varphi_{p}}
$$

The third step is braking duration. So pressure regulation frequency $\omega$ and amplitude $\delta$ are considered as design parameters, and pressure regulation process of ABS is 
simulated by cosine function, then coordinate is transformed (shown in Fig.1). The equations can be gotten as below:

$$
\left.\begin{array}{l}
F^{\prime}=\frac{\delta M}{2} \cos \omega t^{\prime} \\
F^{\prime}=F-\left(F_{0}-\frac{\delta M}{2}\right) \\
t^{\prime}=t-t_{1}
\end{array}\right\}
$$

Eq.7 is converted to original coordinate system, as shown below:

$$
\mathrm{F}=\mathrm{M} \frac{d^{2} S_{2}}{d t^{2}}=\left(\mathrm{F}_{0}-\frac{\delta}{2}\right)+\frac{\delta \cdot \mathrm{M}}{2} \cos \left[\omega\left(t-t_{1}\right)\right]
$$

Solving Eq.8, then it can get the braking distance of second step, so the total value is:

$$
S=S_{1}+S_{2}
$$

\subsection{Initial Conditions and Solution of Model}

Initial conditions of Eq.8 are shown in Eq.10:

$$
\left.\begin{array}{l}
{\frac{d^{2} S}{d t^{2}}}_{t=t_{1}}=a_{0}=g \varphi_{p} \\
S\left(t_{1}\right)=S_{1}=\frac{V_{0}^{2}-V_{1}^{2}}{g \varphi_{p}}
\end{array}\right\}
$$

Table 1. Design parameter values

\begin{tabular}{ccc}
\hline road & $\sigma$ & $\omega$ \\
\hline dry concrete road & 0.2647 & 50 \\
\hline wet concrete road & 0.3333 & 100 \\
\hline
\end{tabular}

To braking requirements of ECE13 on the high friction coefficient road, initial braking speed is $50 \mathrm{~km} / \mathrm{h}$, and ABS braking performance is not significant[4] because it is difficult to find a complete cycle in this moment. Therefore, in Eq.10, for the 
high-speed braking situation, the initial velocity is respectively taken $100 \mathrm{~km} / \mathrm{h}$ and $130 \mathrm{~km} / \mathrm{h}$. Simulated calculation is happened on the dry and wet concrete road, and the peak friction coefficient is respectively 0.9 and 0.8 . $\mathrm{t} 1$ is the time of the brake force growth which depends on the speed of the driver stepped on the brake pedal and the brake system structure, generally, $\mathrm{t}_{1}$ is from $0.15 \mathrm{~s}$ to $0.2 \mathrm{~s}$ in hydraulic brake system, and is $0.3 \mathrm{~s} \sim 0.9 \mathrm{~s}$ [7] in air pressure brake system and the vacuum servo brake. $0.4 \mathrm{~s}$ is taken in this calculation.

Substitute related values in Eq.8, Eq.9 and Eq.10 and solve it, and the results are shown in Tab.2.

Table 2. The brake distance simulation results on the dry and wet concrete road with high-speed braking

\begin{tabular}{ccc}
\hline \multicolumn{2}{c}{ calculation conditions } & calculation results \\
\hline concrete road & Initial velocity $(\mathrm{km} / \mathrm{h})$ & brake distance $(\mathrm{m})$ \\
dry & 100 & 51.382 \\
wet & 100 & 58.129 \\
dry & 130 & 84.946 \\
wet & 130 & 95.317 \\
\hline
\end{tabular}

\section{Road Test and Error Analysis}

\subsection{Road Test Verification}

By comparing the brake distance values which are recorded for a Benz car with ABS in Doc. 8 through test road with results of using the calculation methods in this paper, the brake performance reliability for this car can be evaluated.

Table 3. The brake distance values of the Benz car on concrete road at high speed [8]

\begin{tabular}{ccccc}
\hline $\begin{array}{c}\text { test } \\
\text { program }\end{array}$ & \multicolumn{2}{c}{ test condition } & ABS working & ABS not working \\
concrete road & Initial speed $(\mathrm{km} / \mathrm{h})$ & Brake distance $(\mathrm{m})$ & $\begin{array}{c}\text { Brake distance }(\mathrm{m}) \\
\text { Bry }\end{array}$ \\
\hline 1 & dry & 100 & 41.832 & 50.1284 \\
2 & wet & 100 & 62.753 & 100.1651 \\
3 & dry & 130 & 81.264 & 93.7321 \\
4 & wet & 130 & 97.125 & 138.23541 \\
\hline
\end{tabular}

From Tab.3, it can be told that the brake distance test values are almost the same as the calculated values in this paper except the ones in Program 1, which tested on dry concrete road at an initial speed $100 \mathrm{~km} / \mathrm{h}$. Under the some conditions, the brake distance results were calculated by the method mentioned in Doc.6. Comparing the tested results, the calculated results with the method in Doc.6 and the calculated values in this paper, Fig. 2 can be obtained as below. 


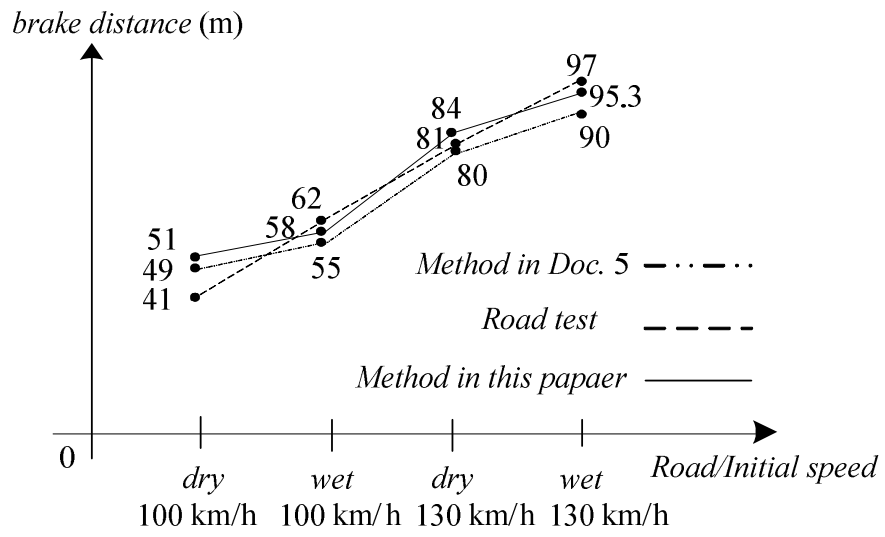

Fig. 2. Brake distance results comparison

The results in Doc.6 were calculated in the condition that the brake system obtained the biggest brake force during continuous brake process with ABS. So ideal ABS model is called and the results should be smaller than the actual ones. Fig. 2 shows that the calculated results are bigger than the ones of the ideal model except Program 1. Consequently, the brake distance calculation method in this paper is reasonable.

\subsection{Error Analysis}

The error between the calculation result with the method in Doc. 6 and tested results is calculated, and is compared with the error between the results from this paper and actual vehicle test. As shown in Fig.3, the calculation result error with the method in this paper fluctuates around the horizontal axis and tends to be smaller, whereas, the result error of Doc.6 tends to be larger. With the increasing of vehicle's speed, the error

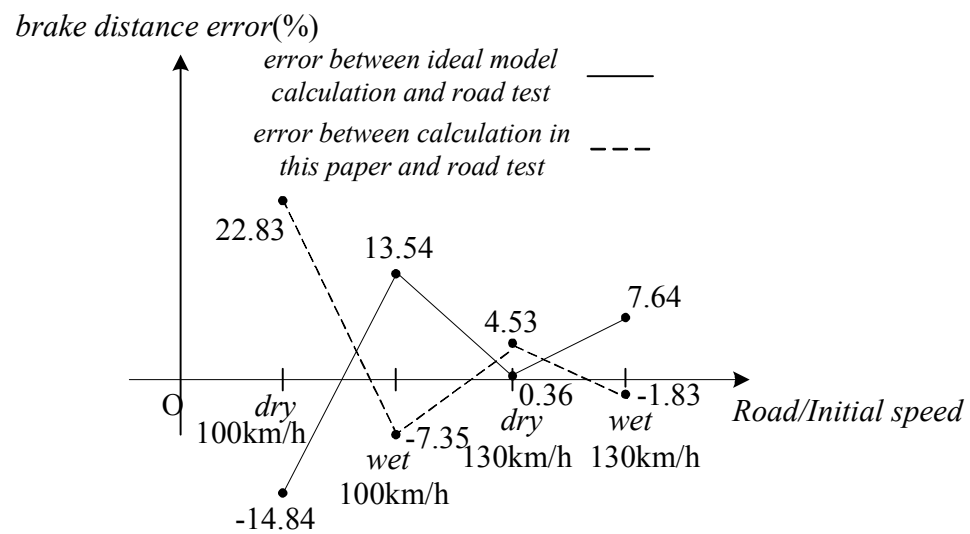

Fig. 3. Brake distance error comparison 
of this paper is rather stationary, and the calculation result is fairly reliable. However, the calculation result error with the method in Doc. 8 is a litter larger. So the calculation result with the method in this paper is reliable and stable.

\section{Conclusions}

1. A calculation model of brake distance is come up, which showed that brake distance for ABS vehicles during continuous brake process is relevant to brake initial speed, road condition, ABS control system's regulating frequency and amplitude. This calculation method can be applied to brake distance calculating and analyzing for various kinds of vehicles.

2. Comparing the brake distance calculation results in this paper with the results from actual vehicle road test, it can be concluded that the calculation in this paper is effective and accurate, which also can evaluated properly on the brake distance results in the test.

3. Evaluation is made on one road test. According to the calculation results in this paper, it can be gotten that the brake distance results of Program 1 are doubtful and need further confirmation.

\section{Acknowledgement}

The work is supported by the Department of Transportation of Jiangxi Province (2009T0053).

\section{References}

1. Alvarez, L., Yi, J., Clarys, X., Horowitz, R.: Emergency braking control with an observer-based dynamic tire/road friction model and wheel angular velocity measurement. Vehicle Syst. Dun 39(2), 81-97 (2003)

2. Schinkel, M., Hunt, K.: Anti-lockbraking control using a sliding mode like approach. In: Proc. American Conf., Anchorage, AK, USA, vol. 3, pp. 2386-2391 (May 2002)

3. Song, J., Kim, H., Boo, K.: A study on anti-lock braking system controller and rear-wheel controller to enhance vehicle lateral stability. In: Proc. IMechE. Part D: J. Automobile Engineering, vol. 221, pp. 777-778 (2007)

4. Sugai, M., Yamaguchi, H., Miyashita, N.N.: New Control Techniaue for Maximizing Braking Force on Antilock Braking System. Vehicle System Dynamics 32, 299-312 (1999)

5. Liu, S.: Research of Bed-testing Evaluation Method of ABS Performance(Master thesis). Wuhan University of Technology, Wuhan (2006)

6. Wang, R.-q., Jiang, k.-j.: Analysis and Calculation of Braking Distance of ABS Automobiles. Journal of Central South Forestry University 25(2), 12-14 (2005)

7. Chen, J.: The:Theory and Practice of ABS Automobile. Beijing Polytechnic University Press, Beijing (1999)

8. Yu, Z.: Automobile Theory. Mechanical Industry Press, Beijing (2006) 